\title{
ANALISE SENSORIAL DE CODORNAS (Coturnix coturni japônica) DEFUMADAS COM TRÊS AROMATIZANTES DIFERENTES
}

\author{
Quitéria Batista dos Santos ${ }^{1}$, Antonio Jackson Ribeiro Barroso ${ }^{2}$, Valdir Nascimento da Silva ${ }^{3}$, \\ Mayk Charles Silva Caldas ${ }^{4}$, José Carlos Ferreira ${ }^{4}$, Flávia Cristina dos Santos Lima ${ }^{4}$ \\ ${ }^{1}$ Discentes do curso técnico em agroindústria do IFPE - campus Belo Jardim. \\ ${ }^{2}$ Tecnólogo em Laticínios e servidor administrativo do IFPE - campus Belo Jardim. \\ ${ }^{3}$ Colaborador do Setor de Carnes do IFPE - campus Belo Jardim \\ ${ }^{4}$ Docentes do IFPE - campus Belo Jardim. \\ *Corresponding author: e-mail: antonio.barroso@belojardim.ifpe.edu.br
}

\begin{abstract}
A pesquisa teve como objetivo principal verificar a aceitabilidade da carne de codorna aromatizada e defumada para exploração comercial. O preparo das aves foi realizado na unidade de processamento de carnes da agroindústria no IFPE - campus Belo Jardim. Colocandoas em salmoura nas concentrações de 1\%, utilizando três tipos de aromatizantes (alecrim, coentro e manjericão). Para o teste de aceitação do produto utilizou-se escala hedônica de 9 pontos para avaliar aroma, cor, consistência e sabor. Os resultados foram avaliados estatisticamente por análise de variância (ANOVA), e as médias comparadas pelo teste de Tukey $(\mathrm{p} \leq 0,05)$. Estatisticamente as amostras não apresentaram diferença significativa para o atributo sabor, sendo portanto, o produto considerado aceito para o consumo. A amostra com alecrin foi a mais aceita obtendo médias superiores a $7 \mathrm{em}$ todos os atributos. Concluindo-se que s codornas aromatizada e defumas com alecrim apresentaram boa aceitação por parte dos julgadores.
\end{abstract}

\section{INTRODUÇÃO}

Considerando que a carne de codorna é praticamente desconhecida no mercado consumidor brasileiro, em razão de se tratar de uma exploração comercial recente, a pesquisa científica sobre o assunto é ainda escassa. A falta de informação sobre as características químicas desta carne torna difícil o conhecimento do seu real valor nutritivo para a alimentação humana. Dentre as poucas pesquisas encontradas sobre codorna a maioria refere-se a produção e ovos, trabalhos com maior ou menor nível de proteína na dieta, e seus efeitos na produção dos mesmos, consumo de dieta e conversão alimentar. O trabalho relacionado à avaliação química da carne de codorna como o de Oliveira (2001), utiliza diferentes linhagens e conteúdo de proteína nas dietas. 


\section{9 a 22 de outubro de 2014 \\ Florianópolis/SC}

As codornas estão se tornando, de maneira rápida, uma espécie de grande interesse econômico, pela sua alta habilidade de converter alimentos inadequados para o consumo humano em fonte de proteína de alta qualidade (Baumgartner, 1994). A carne de codorna é altamente palatável, sendo considerada uma iguaria fina (Panda \& Singh, 1990). Permite todos os tipos de processamento como a elaboração de conservas, defumados e assados diversos.

Segundo Dalmau (2002), a qualidade da carne de codornas é reconhecida desde os povos mais antigos, por seu alto conteúdo em proteínas e por sua escassa infiltração de gordura, aliada a rapidez do ciclo de crescimento, considerado em média de 35 dias para atingir a fase adulta, proporcionando uma carne muito tenra, com preparação gastronômica fácil e rápida, constituindo-se numa carne superior as outras.

A oferta de carne de codornas pode em curto prazo de tempo, se converter em importante fonte alternativa de proteína para o consumo humano. Fatores como o pequeno investimento inicial, a alta resistência das aves às enfermidades e o baixo consumo absoluto de ração, contribuem para estimular a criação dessas aves. Entretanto, as informações disponíveis na literatura sobre a nutrição de codornas ainda são escassas (Silva, et. al., 2007).

Em visão do limitado número de estudos científicos a respeito deste assunto, julgou-se relevante e oportuna a realização desta pesquisa, cujo objetivo é conhecer a opinião dos consumidores sobre codornas aromatizadas com diferentes ervas (alecrim, manjericão e coentro), bem como comparar a qualidade sensorial dessas carnes (Aguiar, 2006).

Grande parte da população mundial e, especialmente a brasileira, está caminhando para se tornar consumidor de perfil mais exigente, não só em termos de sabor, mas também no que se refere à qualidade nutritiva e sanitária dos alimentos que consome, dispondo-se a pagar preços mais elevados por produtos comprovadamente superiores (Oliveira et al., 2000).

A cotonicultura tem apresentado um desenvolvimento bastante acentuado nos últimos tempos. Os principais fatores que contribuem para isso são o excepcional sabor de sua carne, responsável por iguarias finas e sofisticadas e o baixo custo para implantar uma pequena criação, podendo se tornar uma fonte de renda complementar dos pequenos produtores rurais. (Jovem aprendiz rural de batatais, 2008).

De acordo com Moraes \& Ariki (2009) a carne de codorna é escura, macia, saborosa e pode ser preparada da mesma maneira que a de frango de corte. Pesquisas indicam que a carne de codorna é uma excelente fonte de vitamina B6, niacina, B1, B2, ácido pantatênico, bem como de ácidos graxos. Apresenta ainda grandes concentrações de Ferro, Fósforo, Zinco e Cobre quando comparada à carne de frango. A quantidade de colesterol da carne de codorna atinge valores intermediários (76 mg) entre a carne de peito $(64 \mathrm{mg})$ e da coxa e sobrecoxa $(81 \mathrm{mg})$ do frango. A maioria dos aminoácidos encontrados na carne de codorna são superiores aos de frango. Vários autores concluíram que a idade, sexo, linhagem e nutrientes da dieta afetam a composição química da carcaça das aves. 


\section{MATERIAL E MÉTODOS}

No presente estudo foram utilizadas 30 aves (codornas) com peso médio aproximado de $400 \mathrm{~g}$ cada, obtidas no Instituto Federal de Pernambuco campus Belo Jardim no setor de avicultura.

\subsection{Abate das aves de codornas}

Procedeu-se o abate das aves de acordo com as disposições prevista no Regulamento de Inspeção Industrial e Sanitária dos Produtos de Origem Animal e no Regulamento Técnico da Inspeção Tecnológica e Higiênico-Sanitária de Carne de Aves (MAPA, 2012). Após a etapa do abate, as aves foram acondicionadas em sacolas plásticas para serem armazenadas em câmara fria, sendo em seguida resfriadas $4^{\circ} \mathrm{C}$.

\subsection{Preparação e defumação da codorna}

A preparação da codorna defumada ocorreu no setor de agroindústria do IFPE - campus Belo Jardim fazendo uso de três aromatizantes diferentes: alecrim, manjericão e coentro utilizando a mesma concentração, $1 \%$ de aromatizante, onde após o preparo da salmoura (água, sal e aromatizante) as aves foram imersas e permanecerão nesta solução por $24 \mathrm{~h}$ sob refrigeração para a absorção de características de flavor dos aromatizantes.

A defumação foi realizada em defumador artesanal por $2 \mathrm{~h}$ em temperatura de $75^{\circ} \mathrm{C}$, em seguida as aves foram retiradas do defumador e acondicionas em sacolas plásticas, onde permaneceram até o momento do assamento em forno de $180^{\circ} \mathrm{C}$ por 5 minutos com circulação de ar.

\subsection{Análise Sensorial}

A análise sensorial de codorna defumada foi conduzida com 50 provadores não treinados em cabines individuais com a apresentação das amostras em pratos descartáveis com números aleatórios (550 alecrim, 423 coentro e 378 manjericão) acompanhados de água, biscoito água e sal para eliminar possíveis interferências entre as amostras e a ficha de avaliação com escalas hedônica de 9 pontos (ver figura 1) para demonstrar o quanto o provador gostou ou desgostou avaliando cuidadosamente os atributos sensoriais para cada amostra. Os pontos das escalas são distinguidos verbalmente, de modo que possam ser associados a valores numéricos, possibilitando análise estatística dos resultados fazendo uso da anova e submetidos ao teste de Tukey para comparação das médias (Meilgaard et al., 1991). 
Nome:

Ficha de avaliação

Julgador:

1. Você está recebendo três amostras de geleia mista codificadas, por favor, avalie cada amostra individualmente atribuindo notas de acordo com a escala abaixo para cada atributo.

(9) gostei muitíssimo

(8) gostei moderadamente

(7) gostei regularmente

(6) gostei ligeiramente

(5) não gostei, nem desgostei

(4) desgostei ligeiramente

(3) desgostei regularmente

(2) desgostei moderadamente

(1) desgostei muitíssimo

Figura 1 - Ficha de avaliação sensorial.

\subsection{Análise estatistica}

A aceitação do produto pelos provadores foi avaliado utilizando o software ASSISTAT (Silva e Azevedo, 2009), onde foi aplicado o teste de Tukey a 5\% de probabilidade.

\section{RESULTADOS E DISCUSSÃO}

A tabela 1 apresenta os valores médios obtidos na avaliação sensorial, bem como, os respectivos desvios padrões. Observa-se também que as amostras apresentaram bons resultados para o teste sensorial e não houve diferença significativa entre as amostras para os atributos sabor e aroma, apresentando apenas um DMS para os atributos aparência e cor. 


\section{9 a 22 de outubro de 2014 \\ Florianópolis/SC}

Tabela 1 - Escores médios e respectivos desvio-padrão obtidos para carne de codorna defumada e aromatizada com diferentes tipos de aromatizantes.

\begin{tabular}{ccccc}
\hline AMOSTRAS & MACIEZ & COR & ESFARELAMENTO & SABOR \\
\hline 550 & $7,52 \mathrm{a} \pm 1,46$ & $7,30 \mathrm{a} \pm 1,46$ & $7,06 \mathrm{a} \pm 1,58$ & $7,34 \mathrm{a} \pm 1,51$ \\
423 & $5,86 \mathrm{a} \pm 1,93$ & $6,26 \mathrm{a} \pm 1,69$ & $6,52 \mathrm{a} \pm 1,58$ & $6,76 \mathrm{a} \pm 1,96$ \\
378 & $6,34 \mathrm{~b} \pm 2,02$ & $6,44 \mathrm{~b} \pm 1,70$ & $6,36 \mathrm{a} \pm 2,01$ & $6,14 \mathrm{a} \pm 2,43$ \\
\hline
\end{tabular}

*Valores médios numa mesma coluna com letras minúsculas iguais, não diferem significativamente entre si ao nível de 5\% de probabilidade pelo Teste de Tukey.

A amostra 423 apresentou valor próximo aos obtidos por Enke et al. (2010), quando realizou a avaliação sensorial, com provadores treinados, da aparência da carne de codornas submetidas a diferentes dietas, com isso podemos afirmar que os valores encontrados neste trabalho são semelhantes a valores já encontrados por outros pesquisadores que procuram explorar as diversas formas de produção de proteína animal (codornas) para o consumo.

Comparando a média da amostra 378 para o atributo SABOR com os resultados obtidos por Oliveira, (2001) pode-se perceber que a referida amostra encontra-se dentro de padrões sensoriais obtidos com provadores treinados, verificando que a utilização de condimentos naturais para conferir características diferenciadas em produtos defumados como codornas podem ser uma boa alternativa para o aumento da exploração desta ave para o consumo.

Estatisticamente, amostra mais aceita entre os julgadores foi a amostra 550, pois em todo os parâmetros avaliados ela obteve média acima de 7 que corresponde na escala hedônica a gostei moderadamente. Podemos ainda considerar que o uso dos aromatizantes não obteve nenhuma rejeição pelos julgadores ficando a menor nota em 5,86 para APARÊNCIA.

\section{CONCLUSÃO}

A avaliação sensorial da codorna defumada apresentou valores significativos para consumo para os atributos avaliados, não apresentando nenhuma rejeição por parte dos participantes da pesquisa. Portanto, podemos afirmar que o processamento da codorna fazendo uso de alguns condimentos e defumando-a pode ser uma boa alternativa de consumo dessa ave pouco consumida no Brasil, sendo esta mais explorada para a produção de ovos.

\section{REFERÊNCIAS}

AGUIAR, A. P.S. Opinião do consumidor e qualidade da carne de frangos criados em diferentes sistemas de produção. Piracicaba 2006. 71p. Dissertação (Mestre em Ciências) - Universidade de São Paulo (Escola Superior de Agricultura "Luiz de Queiroz").

BAUMGARTNER, J. Japanese quail production, breeding and genetics. J. World's Poult. Sci.. v.50, n.3,p.227 - 235, 1994. 
BRASIL. Ministério da Agricultura. Regulamento da inspeção industrial e sanitária de produtos de origem animal - RIISPOA. Disponível em: <http://www.agricultura.gov.br/online>. Acesso em: 18 de Janeiro de 2014.

DALMAU, A. B. Sistemas produtivos de codornices españa. In: SIMPÓSIO INTERNACIONAL DE COTURNICULTURA, 1, 2002, Lavras. Anais. Lavras: NECTA/DZO/UFLA, p. 49-65, 2002.

DIAS, R. P. DUARTE, T. F. Processamento de linguiça frescal e defumada de caprinos e ovinos. Comunicado técnico, Embrapa - novembro/2007.

ENKE, D. B. S. CALHEIROS, M. N. SILVESTRIN, M. TREPTOW, R. O. SOARES, L. A. S. Características Químicas e Sensoriais da Carne de Codornas Poedeiras (coturnix coturnix japonica) Alimentadas com Diferentes Fontes Protéicas. Rev. Brasil. Hig. Sanid. Animal. v. 04, n. 2, p. 34 - 50, 2010.

JOVEM APRENDIZ RURAL DE BATATAIS. Criação de Codornas. Disponível em: http://jovemaprendizruraldebatatais.blogspot.com/2008/05/criao-de-codornas.html. Acesso em: 9 dezembro de 2013.

MAPA- Ministério da Agricultura Pecuária e Abastecimento, Manual de Inspeção Regulamento Técnico da Inspeção Tecnológica e Higiênico-Sanitária de Carne de Aves, 2012.

MEILGAARD, M.; CIVILLE, G.V.; CARR, B.T. Sensory Evaluation Techniques. 2. ed. Florida: CRC Press, 354p., 1991.

MORAES, V. M. B.; ARIKI, J. Importância da nutrição na criação de codornas de qualidades nutricionais do ovo e carne de codorna. Universidade Estadual Paulista, Jaboticabal-SP, p.97103, 2009. Disponível em: www.biologico.sp.gov.br/rifibi/IIIrifibi/97-103.pdf Acesso em: 8 Janeiro, 2014.

OLIVEIRA .E.G. Avaliação de Desempenho Rendimento de Carcaça, Exigência Protéica, Valor Nutritivo e Avaliação Sensorial de Codornas para Corte. Botucatu, 2001. 96p. (Tese de Doutorado) - USP. SP, 2001.

OLIVEIRA, N. T. E. et al. Exigências de energia e proteína para codornas japonesas machos criadas para produção de carne. In: REUNIÃO ANUAL DA SOCIEDADE BRASILEIRA DE ZOOTECNIA, Viçosa: UFV, Anais..., p.37, 2000.

PANDA, B.; SINGH, R.P. Developments in processing quail meat an eggs. World's Poult. Sci. J. v.46, n.11, p.219 - 234, 1990.

SILVA, E. L. et. al. Efeito do plano de nutrição sobre o rendimento de carcaça de codornas tipo carne. Ciênc. Agrotec., Lavras, v. 31, n. 2, p. 514-522, mar./abr., 2007. 